\title{
Câmbio, juros e inflação: a difícil tríade e o crescimento
}

\author{
João Basílio Pereima Neto* \\ Geraldo Augusto Staub Filho**
}

\begin{abstract}
RESUMO - O atual ciclo econômico (2003/08) presenciou, até o fim de 2007, um marcante período de crescimento, principalmente se comparado ao ciclo anterior, aliado a uma trajetória descendente de juros, inflação e câmbio. Surpreendendo a teoria os bons resultados de crescimento foram obtidos a despeito de um saldo positivo da balança comercial. Os juros, entretanto, em que pese o bom cenário enfrentado, não caíram na velocidade desejada, e agora novos problemas, de estrutura e conjuntura, internos e externos, podem impedir mais uma vez que a taxa básica de juros do Brasil ceda a níveis internacionais.
\end{abstract}

Palavras-chave: Crescimento econômico. Lei de Thirwall. Equilíbrio macroeconômico. Restrição externa.

\section{INTRODUÇÃO}

Durante o atual ciclo de crescimento econômico puxado pela demanda, iniciado em 2003, a taxa de juros apresentou uma lenta trajetória de queda, o câmbio se valorizou e a inflação diminuiu. Os três principais preços da economia, juros, inflação e câmbio, estavam caindo até fins de 2007. A despeito do efeito negativo da valorização cambial sobre as transações correntes e sobre a demanda agregada interna, a combinação baixista contribuiu diretamente para impulsionar a economia brasileira, até então estagnada num pífio crescimento. Mudanças recentes ao longo de 2008 no cenário internacional e doméstico inverteram o movimento de queda. O câmbio principia um movimento de desvalorização, jogando combustível na inflação que sofre pressões altistas advinda de outras fontes internas e externas. Para fazer frente à esta inversão de rota o BACEN, previsivelmente, muda seu posicionamento adotando um política monetária contracionista elevando ainda mais a taxa de juros.

Os efeitos negativos desta inversão macroeconômica sobre a sustentabilidade do crescimento não são difíceis de prever. O novo cenário, com desvalorização cambial,

\footnotetext{
* Doutorando do Programa de Pós Graduação em Desenvolvimento Econômico da UFPR e Professor assistente do Departamento de Economia da mesma instituição. Endereço eletrônico: joaobasilio@ufpr.br

** Mestrando do Programa de Pós Graduação em Desenvolvimento Econômico da UFPR e integrante da equipe do Boletim de Economia e Tecnologia. Endereço eletrônico: gutostaub@yahoo.com.br
} 
desequilíbrio em transações correntes e ameaça de inflação atuará como uma trava à queda futura da taxa de juros e ao crescimento. Sem contar com os novos desmembramentos da crise financeira internacional, que já começa a contaminar o setor real da economia mundial. Nas próximas seções trataremos em mais detalhes da tríade juros, inflação e câmbio, ressaltando como articulações e contradições inerentes podem afetar a continuidade do crescimento da economia brasileira.

\section{CÂMBIO, TRANSAÇÕES CORRENTES E CRESCIMENTO}

Conforme demonstramos na edição no 13 deste boletim (Pereima, 2008) o atual ciclo de crescimento econômico iniciado em 2003 é diferente de outros ciclos no que se refere a contribuição do saldo na balança comercial.

Nos ciclos anteriores, como predito pela teoria, havia uma relação inversa entre saldo em transações correntes e crescimento, evidenciando a tese de que um país para industrializar-se precisa importar bens de capital e insumos diversos e que, portanto, a expansão da renda inevitavelmente conduz a um aumento das importações. Os motivos são tanto a falta de poupança interna (tese da absorção) quanto à existência de lacunas produtivas (tese da substituição de importação). Mas há limites a este tipo de crescimento. Os limites impostos pelo setor externo ao crescimento foram demonstrados inicialmente por Thirwall nos anos 1970 e dependem das elasticidades rendas das exportações e importações, duas variáveis tecnológicas que definem os termos de trocas e a pauta de exportação e importação entre o país e o resto do mundo. A taxa de crescimento econômico de longo prazo, compatível com o equilíbrio nas transações correntes será a divisão das duas elasticidades $\left(g=\varepsilon_{y, x} / \varepsilon_{y, m}\right)$. Qualquer desvio em relação a esta taxa de crescimento equilibrado gerará ciclos que alternam períodos de expansão com desaceleração e por vezes até recessão. Intuitivamente a idéia é simples: se a elasticidade renda das importações for muito alta, maior que 1,0, por exemplo, qualquer aumento da renda interna causará um aumento mais que proporcional das importações. Uma parte maior da demanda interna é deslocada para fora do país, causando déficit na balança comercial e diminuindo com isso a taxa de crescimento efetiva. Para reequilibrar as transações o país terá que diminuir o crescimento. Ou desvalorizar o câmbio. 
No atual ciclo de expansão (2003-2008), curiosamente, a retomada do crescimento foi impulsionada pelas exportações que refletiram um cenário externo favorável e não pelo aumento das importações (teoria da absorção). Isto permitiu ao país obter saldos positivos na balança comercial tanto pelo aumento dos preços dos produtos, como no caso das commodities, quanto pelo aumento do quantum dos produtos exportados, decorrente do alto crescimento mundial observado na década do período.

A teoria está errada? De fato não. As elasticidades renda das exportações e importações dependem do nível tecnológico da economia. É uma característica estrutural do país. Uma mudança na taxa de crescimento de equilíbrio de longo prazo, compatível com equilíbrio externo, somente seria possível por uma mudança na pauta de exportações e importações decorrente de um processo de inovação tecnológica. Foi o que o processo de substituição de importações fez no passado. A despeito do avanço recente que o país fez neste sentido, implementando uma indústria exportadora competitiva (aviação, automobilística, química, naval, etc.), a dependência de commodities para o equilíbrio externo é muito grande. $O$ fato de o país crescer recentemente com saldo positivo na balança comercial reflete o efeito preço externo e o efeito demanda externa por commodities, os quais atuaram no sentido de aliviar a restrição externa e mais que isso, até acumular reservas internacionais. Foi isso que permitiu que as importações aumentassem sem desequilibrar o saldo em transações correntes. É como se a restrição anterior fosse menor em função da elasticidade preço $\left(\varepsilon_{p, x}, \varepsilon_{p, m}\right)$ e da elasticidade da demanda externa $\left(\varepsilon_{y^{*}, x}, \varepsilon_{y^{*}, m}\right)$, ampliando a condição de crescimento equilibrado presente na "regra simples de Thirwall". Os dois últimos termos da expressão abaixo foram favoráveis ao Brasil neste atual ciclo de crescimento e suplantaram o efeito negativo do primeiro termo:

$$
g=\frac{\varepsilon_{y, x}}{\varepsilon_{y, m}}+\frac{\varepsilon_{p, x}}{\varepsilon_{p, m}}+\frac{\varepsilon_{y^{*}, x}}{\varepsilon_{y^{*}, m}} .
$$

Note que a expressão acima não contempla o efeito câmbio sobre as transações correntes, somente o efeito renda e o efeito preço. O risco para a sustentação do atual ciclo de crescimento, compatível com o equilíbrio no setor externo, é que o preço externo ( $p$ ) e a demanda internacional $\left(y^{*}\right)$ são variáveis determinadas exogenamente, fora do alcance das políticas econômicas internas do país. Além disto, são variáveis cíclicas e voláteis, de forma que no longo prazo tem efeitos médios nulos. 
O Gráfico 1 a seguir mostra a evolução da taxa nominal de câmbio e do saldo em transações correntes do Brasil. A linha de tendência mostra a rápida deterioração das condições externas do lado real do setor externo brasileiro.

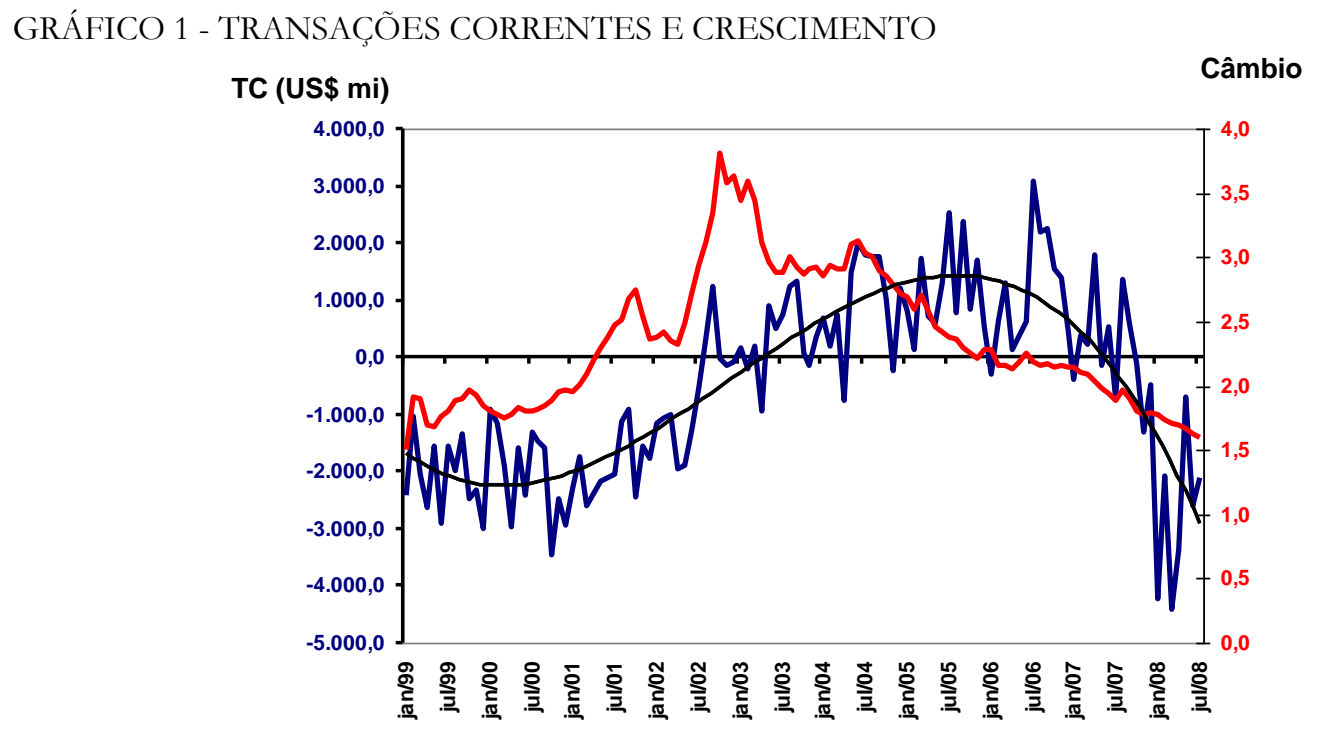

FONTE:BACEN (elaborado pelos autores).

A atual queda livre do saldo em transações correntes, com um déficit acumulado em 12 meses de US\$19,494 bilhões em julho de 2008 (BACEN) ${ }^{3}$, decorre da exaustão dos dois últimos componentes, somados a um aumento do quantum importado estimulado pelo câmbio. $\mathrm{O}$ que antes atuava a favor começa a atuar contra. A bolha dos preços das commodities inflada por especulação financeira está esvaziando e a economia mundial está em franca desaceleração. Tudo leva a crer que estamos voltando para um cenário em que o setor externo voltará impor sua força restritiva. Se é bom para a inflação, é ruim para o equilíbrio externo. Uma alternativa para evitar a deterioração rápida das transações correntes é compensar a queda de preços internacionais, se esta ocorrer em nível significativo como de fato está acontecendo, com desvalorização cambial. Mas do ponto de vista inflacionário uma tal desvalorização é indesejada.

\section{CÂMBIO, TRANSAÇÕES CORRENTES E INFLAÇÃO}

\footnotetext{
${ }^{3} \mathrm{O}$ resultado já representa $90 \%$ da previsão que o governo fez para todo o ano de 2008 . A queda do saldo em transações correntes foi muito mais rápida e será muito maior do que pensam os analistas do governo.
} 
Além da restrição externa via financiamento do balanço de pagamentos, o câmbio também desempenha um papel chave na dinâmica dos preços internos. Neste ponto aparece a primeira contradição entre a necessidade de desvalorizar o câmbio para equilibrar o balanço de pagamentos e a necessidade de apreciá-lo para combater inflação.

Desde o Plano Real de 1994, portanto por um período de quase quinze anos, o país convive com câmbio valorizado como prática de combate à inflação. Seja no Plano Real, quando o câmbio era fixo, seja após, quando passou a flutuar, a política macroeconômica adotada no país foi de manter a taxa cambial valorizada no intuito de diminuir os custos dos bens e insumos importados e ao mesmo tempo aumentar a oferta externa criando competição no mercado e com isso evitando inflação interna. Neste período o câmbio sempre atuou como uma âncora dos preços. Na luta recente contra a inflação o papel coadjuvante do câmbio é responsável por boa parte do sucesso do sistema de metas de inflação. ${ }^{4}$ O Gráfico 2 a seguir mostra a trajetória conjunta da inflação e da taxa nominal de câmbio.

GRÁFICO 2 - CÂMBIO E INFLAÇÃO NO BRASIL NO MÉDIO PRAZO

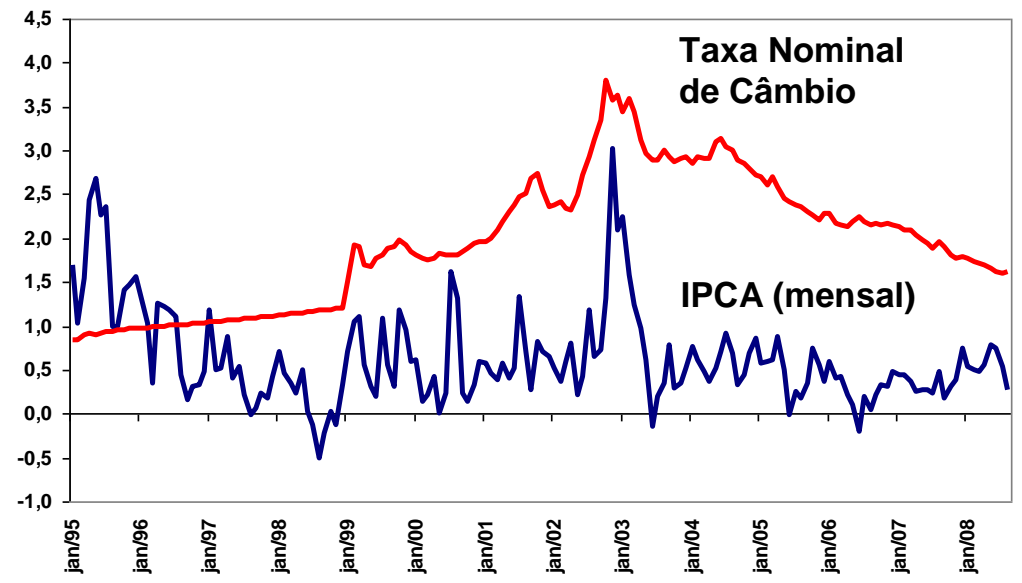

FONTE: BACEN. (elaborado pelos autores). Taxa de câmbio: Taxa Livre - Dólar americano (compra) - Média de período - mensal.

A trajetória da inflação e do câmbio, e o respectivo uso do câmbio como uma variável a serviço da política monetária, devem ser contrastadas com o resultado observado no saldo do setor externo e no crescimento da economia demonstrados no Gráfico 2 acima. Passado o surto

\footnotetext{
4 Os anos de alta inflação em 2002 e 2003 foram períodos de exceção à prática do câmbio valorizado. Em novembro de 2002, o IPCA mensal foi de 3,02\%am atingindo seu nível mais alto no período pós real. O descontrole de preços ocorreu diante de um período especulativo com saída maciça de capitais, decorrente dos sucessivos déficits nas transações correntes do período anterior e da perda de reservas. A parte os problemas políticos da ascensão da esquerda ao poder, o que causou o ataque especulativo foi a deterioração do balanço de pagamentos por conta da restrição externa. Não foi a toa que até 2002, o país não cresceu, como demonstrado no Gráfico 1.
} 
inflacionário de 2002 e 2003, na ausência de crescimento acelerado por insuficiência de demanda a inflação rapidamente caiu em meados de 2003. Em jul/03 houve até uma deflação de -0,15\%.

O saldo positivo das transações correntes após 2003, além do momento externo favorável (preços das commodities e demanda externa em alta), contou também com este enorme empurrão da desvalorização cambial decorrente da especulação de 2002. Como o câmbio se apreciou lentamente de 2003 em diante o impacto das três forças (preços internacionais das commodities, demanda externa e desvalorização do câmbio) foi a origem do atual ciclo de crescimento com saldo positivo nas transações correntes, o que justifica o efeito das elasticidades câmbio e demanda externa que mais do que compensaram a restrição de Thirwall, como argumentado anteriormente. A queda da taxa juros após 2005 somente foi possível graças à combinação de inflação baixa e câmbio em processo de valorização, que pode ser observada no período final do Gráfico 2.

No que se refere ao curto prazo recente, até julho de 2008, a economia enfrentou um novo surto de inflação. Mas desta vez por uma causa totalmente alheia ao câmbio. Como pode ser visto no Gráfico 3 a seguir, houve um aumento de inflação ao mesmo tempo em que o câmbio se valoriza. Desta vez a inflação foi causada em parte por choque de oferta com elevação dos preços internacionais das commodities e por demanda interna. Desta vez a inflação não esteve associada ao câmbio.

GRAFICO. 3 - CÂMBIO E INFLAÇÃO NO BRASIL NO CURTO PRAZO

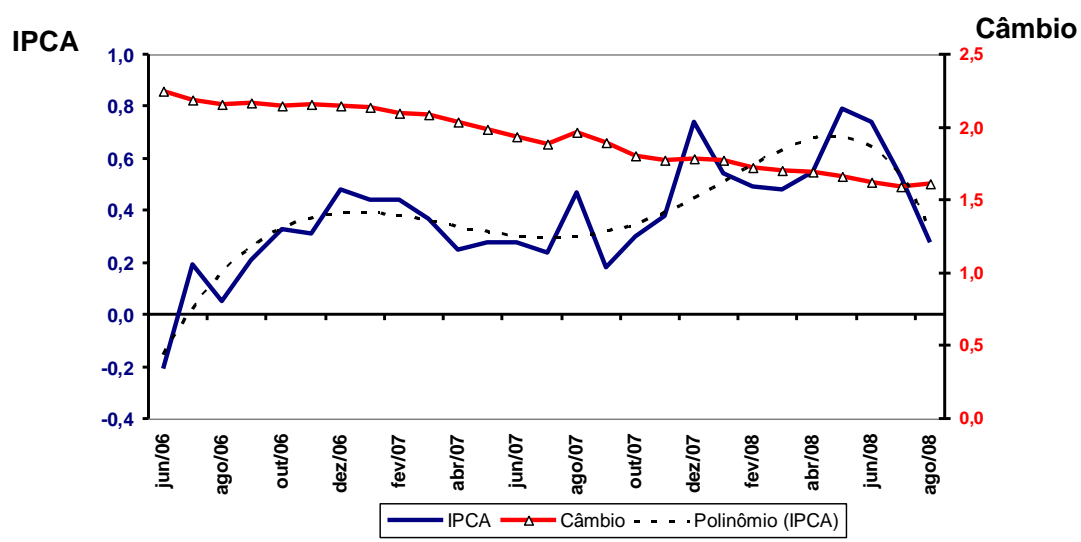

FONTE: BACEN (elaborado pelos autores). Taxa de câmbio: Taxa Livre - Dólar americano (compra) - Média de período - mensal.

Mas os dados recentes do setor externo apontam para uma continuidade dos déficits externos e de uma tendência de médio prazo à desvalorização cambial. $\mathrm{Na}$ ótica do Banco 
Central isto não é desejável pois afetaria os preços internos gerando inflação forçando-o elevar a taxa de juros para atrair capital financeiro.

Neste ponto se revela outro obstáculo imposto pela tríade. A desvalorização cambial é necessária ao equilíbrio do balanço de pagamentos, mas é indesejada do ponto de vista da inflação. Com uma demanda interna aquecida, não há muito espaço inflacionário para suportar desvalorizações.

\section{CÂMBIO, TRANSAÇÕES CORRENTES E JUROS}

Por um longo período o nível da taxa de juros tem permanecido alto no Brasil sob a alegação de combater a inflação. Diretamente por inibir consumo e investimentos. Indiretamente por atrair um fluxo elevado de capital financeiro, que ao ser convertido em reais, amplia a oferta de moeda estrangeira e provoca uma valorização cambial. Os preços importados, relativamente mais baratos, ajudam a combater a inflação.

A conjuntura macroeconômica internacional atual é favorável à queda de preços, especialmente commodities. Isto tem um efeito ambíguo para o Brasil. Por um lado é benéfico ao evitar inflação. Mas tem um impacto perverso no saldo da balança comercial, atualmente já comprometido pelo aumento desproporcional da importação de peças, matérias primas diversas e bens de capital.

Doravante a tendência é que o BACEN use a política monetária restritiva não para combater preços diretamente, que estão em queda, mas para equilibrar o balanço de pagamentos. E deverá fazer isso exatamente num momento em que o cenário internacional apresenta uma grande diminuição de liquidez. O contexto internacional deverá impor uma sobrecarga à política monetária, o que poderá resultar em taxas de juros maiores que o normal para atrair o escasso capital estrangeiro.

\section{A TRÍADE: CONCLUSÃO}

Desde 1994 até 2002, a política macroeconômica vigente trocou crescimento por combate à inflação. Para tanto o país combinou câmbio valorizado e juros altos. Para ter controle sobre a inflação, sobre o câmbio e financiar os déficits em transações, abriu mão do controle da taxa de juros a qual atingiu níveis reais estratosféricos. 
De agora em diante a tendência é de inversão na tríade. Os preços em queda deveriam abrir uma janela para retomada da queda dos juros. O espaço existente no passado recente para uma redução mais acentuada na taxa de juros foi ignorado pela autoridade monetária. Agora se abre uma nova oportunidade com a queda dos preços. No entanto esta janela será estreitada, senão totalmente fechada, pelo desequilíbrio do setor externo. Os juros altos de agora estarão à serviço do financiamento do déficit externo, em franca progressão, para além das expectativas de todos.

Mudanças estruturais maiores no mix macroeconômico do país são necessárias, e dentre elas é preciso pensar em diminuir o grau de mobilidade internacional de capital, especialmente os de estrutura financeira especulativa. O problema é que o momento de fazê-lo é impróprio, devido à crise internacional, à redução de liquidez nos mercados e ao crescente déficit em transações correntes.

Nos últimos anos o governo perdeu duas grandes oportunidades para aperfeiçoamento marginal do conjunto de políticas macroeconômicas. Foi lento e comedido em baixar juros ao longo de 2006 e 2007 e não diminuiu a exposição do país aos fluxos especulativos, sob o argumento de que o acúmulo de reservas resolveria todos os problemas.

A política macroeconômica do país não é reflexo tão somente das escolhas técnicas, amparadas em teorias, métodos e previsões de difícil concertação, mas também de escolhas que somente a economia política pode explicar. 